\title{
Editorial: The Androgen Receptor in Breast Cancer
}

\author{
Anna Tesei ${ }^{1 *}$ and Gabriella Castoria ${ }^{2 *}$ \\ ${ }^{1}$ Biosciences Laboratory, Istituto Scientifico Romagnolo per lo Studio e la Cura dei Tumori (IRST), Istituto di Ricovero e Cura \\ a Carattere Scientifico (IRCCS), Meldola, Italy, ${ }^{2}$ Dipartimento di Medicina di Precisione, Università della Campania \\ "L. Vanvitelli", Naples, Italy
}

Keywords: androgen receptor, breast cancer, triple-negative breast cancers, anti-androgen therapy, non-genomic effects of the androgen receptor

\section{Editorial on the Research Topic}

The Androgen Receptor in Breast Cancer

Androgen receptor (AR) is often overexpressed in breast cancer $(\mathrm{BC})(1-3)$ and is the prevalent sex steroid receptor in "in situ," invasive and metastatic BC (4-8). Moreover, up to $30 \%$ of triple negative breast cancers (TNBCs), the most aggressive forms of $\mathrm{BC}$, express $\mathrm{AR}$, which is also the only sex steroid receptor detectable in $\mathrm{BC}$ metastases and in metastatic lesions resected at autopsy (9-11). Although several findings support a role for androgen/AR axis in BC, its involvement in the pathogenesis and progression of this cancer remains debated, and the predictive and prognostic role of AR in TNBCs is even less clear.

By gene expression analysis of several BC data sets, Lehmann and colleagues identified six different TNBC subtypes (12). The luminal AR (LAR) subtype differs from the others in gene expression profile and ontology. Analysis of gene expression in the LAR subtype was consistent with a subset of estrogen receptor (ER) ${ }^{-} / \mathrm{AR}^{+} \mathrm{BCs}$ (also known as molecular apocrine tumors), which express genes commonly detected in luminal tumors, such as XPB-1, SCUBE2, SPDEF, and FOXA1 $(13,14)$. These findings, together with the observed sensitivity of LAR-derived cells to the antiandrogen bicalutamide, strengthened the concept that AR is a key component of the LAR-TNBC subtype and that AR-targeted therapies may be effective against BCs expressing this hormone receptor (12). The benefits of anti-androgen treatment for AR-expressing BCs have since become the subject of an ongoing discussion among oncologists.

The historical success of AR targeting in prostate cancer (PC) has provided a proof-of-principle for its application in BC therapy. Specifically, the development of new, more effective, and safer ARtargeted agents has once again opened up the debate on whether or not to use these compounds in BCs and especially in TNBCs, for which no specific treatment guidelines are available and systemic chemotherapy remains almost the only option in both early and advanced stages of the disease. Anti-androgen therapies showed promising results in preclinical models of BCs (15-18) and several clinical trials have evaluated the efficacy of this approach in patients with $\mathrm{AR}^{+} \mathrm{TNBC}$; very encouraging data from three trials investigating the use of bicalutamide, abiraterone acetate, and enzalutamide report clinical benefit in about one in five patients (19-21). Of note, as in PC, the onset of a hormone-refractory state following prolonged use of selective androgen receptor modifiers is expected, and the findings from clinical trials make a case for identifying predictive response factors and therapeutic combinations in order to translate advancements in the field of $\mathrm{BC}$ into clinical practice. 
The complexity of AR action is further underscored by studies on non-genomic actions mediated by the hormone receptor in BCs. The ligand-bound receptor interacts with various signaling effectors in the extranuclear compartment of target cells. Depending on cell type and hormone concentration, androgentriggered association of AR with the tyrosine kinase Src activates Src-dependent signaling pathway, leading to cell proliferation, while hormone-stimulated interaction between AR and filamin A controls machinery driving cell motility and invasiveness (22). Of note, the role of Src and PI3K-dependent signaling pathways in promoting invasiveness triggered by androgen/AR axis has been recently dissected in various TNBC cell subtypes (23). These and other similar findings might pave the way toward the identification of biomarkers predictive of TNBC malignancy and the exploration of novel compounds for clinical application.

In this Research Topic, we have invited leading groups to contribute review and original research articles on the role of AR in BC. Three reviews within this Research Topic address some of the questions still pending and identify challenges in the field, with the aim of re-examining the intricate molecular landscape of $\mathrm{AR}$ and offering new clues as to its prognostic and therapeutic value in BCs. Bleach and Mcllroy discuss the complexity of ARdriven mechanisms within the context of our current knowledge of steroid intracrinology in BC. The paper describes the action of key mediators of transcriptional or non-transcriptional ARinduced events in $\mathrm{BC}$, with particular emphasis on the role of intracrine ligands and their fluctuations. Interestingly, the review outlines the role of $\mathrm{AR} / \mathrm{ER} \alpha$ crosstalk occurring at transcriptional level in BCs, together with factors that modulate their interaction. The simultaneous targeting of $\mathrm{AR}$ and $\mathrm{ER} \alpha$ is an intriguing proposition and might provide a valid approach to overcome therapeutic resistance in BC.

Over the last decade, conflicting evidence has been reported on the role of AR in BCs. Giovannelli et al. review major findings on the biology of $\mathrm{AR}$ in $\mathrm{BC}$, with a focus on its prognostic and predictive role in TNBCs. The authors discuss the development of future therapeutic strategies in this BC subtype in light of the group's most recent discoveries obtained using new site-specific compounds that specifically perturb the non-genomic mechanism mediated by AR in preclinical models of TNBCs (23). Inhibition of this functional action of AR may enhance the effect of traditional AR transcriptional inhibitors and warrant further investigation in clinical models of TNBCs.

Lastly, Chen et al. explore the role of AR and AR-related mechanisms in various $\mathrm{BC}$ subtypes, with a focus on experimental

\section{REFERENCES}

1. Niemeier LA, Dabbs DJ, Beriwal S, Striebel JM, Bhargava R. Androgen receptor in breast cancer: Expression in estrogen receptor-positive tumors and in estrogen receptor-negative tumors with apocrine differentiation. Mod Pathol (2010) 23:205-12. doi: 10.1038/modpathol.2009.159

2. Hickey TE, Robinson JLL, Carroll JS, Tilley WD. Minireview: The androgen receptor in breast tissues: Growth inhibitor, tumor suppressor, oncogene? Mol Endocrinol (2012) 26:1252-67. doi: 10.1210/me.2012-1107 limitations and issues encountered in translating research from bench to bedside. The review spotlights the need to develop more appropriate AR detection methods and to identify new markers of AR responsiveness for better stratification of patients who might benefit from AR-targeted treatments.

BC therapy has evolved over the years from surgery, chemotherapy, radiation therapy, and hormone therapy to combinatorial treatments $(24,25)$. However, many patients, particularly TNBC patients, still experience a very high rate of recurrence, regardless of subtype. Because of the paucity of available therapies for as well as the intrinsic insensitivity of TNBCs to radiation therapy (26), the development of new radiosensitizing strategies is needed to improve clinical outcomes. The research article by Michmerhuizen et al. reports promising data on the effects of seviteronel, a non-steroidal selective CYP17-lyase inhibitor that blocks AR activation. Although the compound exhibits a limited effect in monotherapy, it shows great promise in radiosensitizing $\mathrm{AR}^{+} \mathrm{TNBC}$ in preclinical models. These findings may help expand the toolkit of radiotherapists and oncologists.

Differences in BC outcome among specific patient groups based on age, ethnicity, disability, and other factors are widely recognized. By comparing the biological characteristics of Tanzanian and Italian BC patients matched for date of and age at diagnosis, the research article by Bravaccini et al. examines the role of $\mathrm{AR}$ as a prognostic marker in a Sub-Saharan African setting, where access to healthcare and cancer prevention services is extremely poor. The paper reports that TNBCs analyzed among the Tanzanian population expressed very high AR levels, opening up new therapeutic perspectives in this low-income country.

In recent years, precision medicine strategies have yielded very encouraging results that lay the groundwork for more personalized diagnosis and treatment of AR-expressing BCs. However, much work is still needed to further explore the molecular and clinical aspects of this disease. The efforts of multidisciplinary teams combining molecular endocrinologists, oncologists, clinicians, and radiotherapists are expected to deliver high-quality research and therapeutic advances in the global battle against BC.

\section{AUTHOR CONTRIBUTIONS}

AT and GC wrote, reviewed, and approved the content of this editorial. All authors contributed to the article and approved the submitted version. 
receptor positive breast cancers. Breast Cancer Res Treat (2010) 124:607-17. doi: 10.1007/s10549-010-0761-y

6. Buchanan G, Birrell SN, Peters AA, Bianco-Miotto T, Ramsay K, Cops EJ, et al. Decreased androgen receptor levels and receptor function in breast cancer contribute to the failure of response to medroxyprogesterone acetate. Cancer Res (2005) 65:8487-96. doi: 10.1158/0008-5472.CAN-04-3077

7. Lønning PE. Additive endocrine therapy for advanced breast cancer back to the future. Acta Oncol (Madr) (2009) 48:1092-101. doi: 10.3109/02841860903117816

8. Gucalp A, Traina TA. Triple-negative breast cancer: Role of the androgen receptor. Cancer J (2010) 16:62-5. doi: 10.1097/PPO.0b013e3181ce4ae1

9. Lea OA, Kvinnsland S, Thorsen T. Improved Measurement of Androgen Receptors in Human Breast Cancer. Cancer Res (1989) 49:7162-7.

10. Park S, Koo J, Park HS, Kim JH, Choi SY, Lee JH, et al. Expression of androgen receptors in primary breast cancer. Ann Oncol (2009) 21:488-92. doi: 10.1093/ annonc/mdp510

11. Cimino-Mathews A, Hicks JL, Illei PB, Halushka MK, Fetting JH, De Marzo $\mathrm{AM}$, et al. Androgen receptor expression is usually maintained in initial surgically resected breast cancer metastases but is often lost in end-stage metastases found at autopsy. Hum Pathol (2012) 43:1003-11. doi: 10.1016/ j.humpath.2011.08.007

12. Lehmann BD, Bauer JA, Chen X, Sanders ME, Chakravarthy AB, Shyr Y, et al. Identification of human triple-negative breast cancer subtypes and preclinical models for selection of targeted therapies. J Clin Invest (2011) 121:2750-67. doi: 10.1172/JCI45014

13. Farmer P, Bonnefoi H, Becette V, Tubiana-Hulin M, Fumoleau P, Larsimont D, et al. Identification of molecular apocrine breast tumours by microarray analysis. Oncogene (2005) 24:4660-71. doi: 10.1038/sj.onc.1208561

14. Doane AS, Danso M, Lal P, Donaton M, Zhang L, Hudis C, et al. An estrogen receptor-negative breast cancer subset characterized by a hormonally regulated transcriptional program and response to androgen. Oncogene (2006) 25:3994-4008. doi: 10.1038/sj.onc.1209415

15. Naderi A, Chia KM, Liu J. Synergy between inhibitors of androgen receptor and MEK has therapeutic implications in estrogen receptor-negative breast cancer. Breast Cancer Res (2011) 13:R36. doi: 10.1186/bcr2858

16. Nahleh Z. Androgen receptor as a target for the treatment of hormone receptor-negative breast cancer: an unchartered territory. Futur Oncol (2008) 4:15-21. doi: 10.2217/14796694.4.1.15

17. Ni M, Chen $\mathrm{Y}$, Lim E, Wimberly H, Bailey ST, Imai $\mathrm{Y}$, et al. Targeting Androgen Receptor in Estrogen Receptor-Negative Breast Cancer. Cancer Cell (2011) 20:119-31. doi: 10.1016/j.ccr.2011.05.026

18. Jing Y, Cui D, Guo W, Jiang J, Jiang B, Lu Y, et al. Activated androgen receptor promotes bladder cancer metastasis via Slug mediated epithelial-mesenchymal transition. Cancer Lett (2014) 348:135-45. doi: 10.1016/j.canlet.2014.03.018
19. Gucalp A, Tolaney S, Isakoff SJ, Ingle JN, Liu MC, Carey LA, et al. Phase II trial of bicalutamide in patients with androgen receptor-positive, estrogen receptor-negative metastatic breast cancer. Clin Cancer Res (2013) 19:550512. doi: 10.1158/1078-0432.CCR-12-3327

20. Bonnefoi H, Grellety T, Tredan O, Saghatchian M, Dalenc F, Mailliez A, et al. A phase II trial of abiraterone acetate plus prednisone in patients with triplenegative androgen receptor positive locally advanced or metastatic breast cancer (UCBG 12-1). Ann Oncol (2016) 27:812-8. doi: 10.1093/annonc/ mdw067

21. Traina TA, Miller K, Yardley DA, Eakle J, Schwartzberg LS, O'Shaughnessy J, et al. Enzalutamide for the treatment of androgen receptor-expressing triplenegative breast cancer. J Clin Oncol (2018) 36:884-90. doi: 10.1200/ JCO.2016.71.3495

22. Castoria G, Auricchio F, Migliaccio A. Extranuclear partners of androgen receptor: at the crossroads of proliferation, migration, and neuritogenesis. FASEB J (2017) 31:1289-300. doi: 10.1096/fj.201601047R

23. Giovannelli P, Di Donato M, Auricchio F, Castoria G, Migliaccio A. Androgens Induce Invasiveness of Triple Negative Breast Cancer Cells Through AR/Src/PI3-K Complex Assembly. Sci Rep (2019) 9(1):4490. doi: 10.1038/s41598-019-41016-4

24. Abe O, Abe R, Enomoto K, Kikuchi K, Koyama H, Masuda H, et al. Effects of radiotherapy and of differences in the extent of surgery for early breast cancer on local recurrence and 15-year survival: An overview of the randomised trials. Lancet (2005) 366:2087-106. doi: 10.1016/S0140-6736(05)67887-7

25. Clarke M. Meta-analyses of adjuvant therapies for women with early breast cancer: The Early Breast Cancer Trialists' Collaborative Group overview. Ann Oncol (2006) 17(Supplement 10):x59-62. doi: 10.1093/annonc/mdl238

26. Kyndi M, Sørensen FB, Knudsen H, Overgaard M, Nielsen HM, Overgaard J, et al. Estrogen receptor, progesterone receptor, HER-2, and response to postmastectomy radiotherapy in high-risk breast cancer: the danish breast cancer cooperative group. JCO (2008) 26:1419-26. doi: 10.1200/JCO. 2007.14.5565

Conflict of Interest: The authors declare that the research was conducted in the absence of any commercial or financial relationships that could be construed as a potential conflict of interest.

Copyright $\odot 2021$ Tesei and Castoria. This is an open-access article distributed under the terms of the Creative Commons Attribution License (CC BY). The use, distribution or reproduction in other forums is permitted, provided the original author $(s)$ and the copyright owner(s) are credited and that the original publication in this journal is cited, in accordance with accepted academic practice. No use, distribution or reproduction is permitted which does not comply with these terms. 